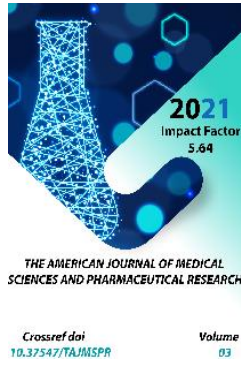

\title{
Prevalence Of Chronic Non-Communicable Diseases Among Women In The City Of Andijan
}

\author{
Gulchehra Usmonovna Nazarova \\ Assistant Professor, Candidate Of Medical Sciences, Andijan State Medical Institute, Uzbekistan
}

Copyright: Original

content from this work

may be used under the

terms of the creative

commons attributes

4.0 licence.

\section{ABSTRACT}

The modern screening test was performed in 1323 women, which live in Fergana valley. Our results have shown that first of all, the more cases were polipathy. The second, more cases were in 35-49 age women. Third, we found evidence it importance of epidemiological study of findings polipathy and we recommend this project to using in practice.

\section{KEYWORDS}

Diseases, organ pathology, research, combined diseases, clinical observations, chronic noncommunicable diseases.

\section{INTRODUCTION}

The plurality of diseases and the multiple organ pathology in one and the same person is

already attracting the attention of clinicians and researchers. However, the idea of 
combined and combined diseases, bi - and polycasual causes of hard clinical points from them are based mainly on clinical observations or in single epidemiological studies on unorganized rural populations. It should be mentioned that a rather long period of time has elapsed since the beginning of population studies devoted to the study of the epidemiological patterns of the main chronic non-infectious diseases. During this time, the methods of the high-risk population strategy have changed and improved significantly, most importantly, evidence and true information that is extremely necessary for the effective and safe prevention of non-infectious pathologies has begun to come to light. If at the "dawn" of epidemiology it was mainly about the population study of individual diseases, then in recent years there have been reports of the study of multiple risk factors and diseases.

\section{PURPOSE OF THE STUDY}

To study the prevalence of the main multiple chronic non-infectious diseases among the unorganized population of women of fertile age in the city of Andijan, Fergana Valley.

\section{MATERIAL AND METHODS}

Districts of the city of Andijan were selected as objects of research, which, according to statistical indicators, all the requirements of representativeness.

From the voter lists of the old and new parts of the city (the electoral campaign preceding the start of the study) using tables of random numbers, after verification of addresses in the Central Address Bureau of Andijan and ZhEKs, a 10\% representative sample of women aged 1549 was formed in the amount of 1598 people (in the old part of the city - 1087 and in the new district - 510 women). In total, out of 1598 selected for the study, 1323 women (82.1\%) came and were examined. In the old district, 912 women were examined, which is $80.4 \%$ of the total selected contingent for the examination of women. This work is epidemiological and used standard, unified research methods, criteria for evaluating the data obtained and classifications recommended by WHO for population studies and used in the practice of preventive medicine.

The survey was carried out in the morning, on an empty stomach and included the following epidemiological methods: questionnaire, instrumental and biochemical.

\section{SURVEY METHODS}

The population was interweaved according to the standard WHO questionnaires for the detection of cardiovascular diseases (CVD), chronic obstructive pulmonary disease (COPD), urinary system diseases (USD), diabetes mellitus (DM) and anemia.

Instrumental: ECG at rest in 12 conventional leads and assessment from the standpoint of the Minnesota code, X-ray and ultrasound studies according to indications.

In addition, blood pressure was assessed based on the recommendations of the IOC and WHO (1999), for arterial hypertension (AH) values of $\mathrm{SBP} \geq 140 \mathrm{~mm} \mathrm{Hg}$ and $\mathrm{DBP} \geq 90 \mathrm{~mm} \mathrm{Hg}$. Anthropometric studies were carried out on conventional medical scales and stadiometer with an accuracy of $0.5 \mathrm{~cm}$ - height and 0.1 weight.Biochemical studies: determination of the concentration of trace elements $(\mathrm{Na}, \mathrm{K}, \mathrm{Ca}$, $\mathrm{Mg}$, chlorine, iron, phosphorus) on atomic absorption spectrophotometers such as AAS - 
3 and AAS - IN and determination of lipid levels on the FP - 901 autoanalyzer.

The data obtained were processed on a computer IBMAT - 370 using statistical software packages (Jn. Form, BMOP 7D, SAS 79, SAS - 82), using Fisher - Student statistics methods with calculating the arithmetic mean (M), standard deviation, mean arithmetic error $(\mathrm{m})$, and, if necessary, the rank correlation coefficient $(r)$ and its confidence level.

\section{RESULTS AND DISCUSSION}

One of the main tasks of our research, which we tried to solve, was to identify multiple pathologies in order to develop optimal approaches to the prevention of polypathies among LPV at the individual and population levels. In doing so, we were largely guided by the well-known literature data .

Studies have shown that $86.3 \%$ of women have chronic multiple organ pathology with a number of diseases of 2 or more (polypathies). Only $23.5 \%$ of LPV had no chronic non-infectious diseases (CND). $56.7 \%$ had one chronic noninfectious pathology, $84.8 \%$ had three, $57.9 \%$ had four, and $41.8 \%$ had all 5 chronic diseases at the same time.

Most often, the examined people have a combination of two and three chronic diseases; in almost half of the LPV, a combination of four or five non-infectious diseases is observed. Such a significant increase in the prevalence of polypathy cannot but be alarming, since such epidemiological trends in HCNZ are closely related to firm "endpoints" of the population. Apparently, for a clear epidemiological explanation of this fact, a further more in-depth prospective study of the selected population object is required.
It was revealed that the prevalence of polypathy increases from the age group to 20 years (43.0\%), then, as age increases, the frequency of multiple chronic diseases increases linearly and statistically significantly, amounting to $76.2 \%$ in the age group $20-29$ years ( $P<0,01), 94.7 \%$ under the age of $39(P$ $<0.01)$ and $98.6 \%$ in the age group $40-49$ years $(P<0.05)$. Most often, the surveyed women 15 - 49 years old have 2 CHD (84.7\%), then a combination of 5 CHD (41.8\%), approximately the same frequency is recorded in women with one and four CHD in $56.7 \%$ and $57.9 \%$ cases respectively.

At the age of up to 20 years, only $4.4 \%$ of the surveyed did not have $\mathrm{CHD}$. At least one $\mathrm{Cl}$ was detected in $10.5 \%$ of the surveyed, a combination of two $\mathrm{Cl}$ was noted in $12.3 \%$ of the surveyed, $3 \mathrm{Cl}$ - in $7.9 \%, 4 \mathrm{Cl}$ - in $5.3 \%$ and $5 \mathrm{Cl}$ - in $2.6 \%$ women.

Among women under the age of 29 , only $7.8 \%$ of the surveyed did not have chronic multiple organ pathologies; at least one CND was noted in $17.4 \%$. The combination of two or more chronic multiple organ pathologies was found in half of the surveyed - in 50.9\%. $12.3 \%$ of women had one chronic pathology, $15.7 \%$ had three, $10.7 \%$ had four, and $3.6 \%$ had all 5 chronic diseases at the same time.

In the age group under 39 years old, $94.7 \%$ of women have polypathies with a number of diseases of 2 or more. Among them, only 11.3\% of women did not have CHD, 21.4\% had one CHD, $26.0 \%$ had 2 CHD, $21.4 \%$ had three, $13.8 \%$ had four and 6, 7\% - all 5 CNDat the same time. A combination of two or more chronic diseases is quite common $(59.6 \%, \mathrm{P}<0.01)$. 
According to our data, the highest incidence of polypathy is noted among women aged $40-49$ years $-98.6 \%$. In this group, only $0.3 \%$ of the examined did not have the analyzed pathologies. The surveyed had 1 CHD $-4.7 \%, 2$ CHD - in $15.6 \%, 3$ CHD - in $19.9 \%, 4$ CHD - in $23.1 \%$ and 5 CHD - in $35.0 \%$ of cases.

Such a picture of the epidemiological indicators of the incidence of polypathy and the linearly increasing population pyramid is most likely associated with the accumulation of certain risk factors, as well as physiological and pathological features occurring in the body of women with increasing age. In addition, with age, there is a decrease in the activity of the sympathoadrenal system, which is associated with the prevalence of certain CND and, on the other hand, an increase in the frequency of polypathies can be associated with material difficulties, problems with employment, a deterioration in the quality of nutrition, the presence of chronic infections of the female genital area, as well as disorders psychoemotional status as a result of frequent childbirth and pregnancies.

This explanation is found in the literature of a number of countries, including the $\mathrm{CIS}$ countries, in particular in the Central Asian states [2, 8, 9, 10]. However, it should be emphasized that it is possible to prove the role of the above mentioned reasons (as risk factors) in the occurrence and prevalence of polypathy only through prospective studies, because the studied epidemiological "agent core" can serve as a cause (risk factor) of the disease, and be a component in other reasons. Of course, in order to identify the patterns of dependence of the prevalence of multiple chronic diseases on regional (endemic) risk factors, appropriate epidemiological studies are needed, which will largely help solve the current problems of the reproductive health of the female population.

\section{CONCLUSION}

1. Among the female population of fertile age, there is a fairly high prevalence of multiple chronic diseases (polypathies). Almost half of women have a combination of four or five chronic pathologies.

2. Intensive accumulation of chronic multiple organ pathologies with the number of diseases of two or more, bi - and polycausal risk factors occurs in the reproductive age of the female population. A kind of "peak" of polypathies and various combinations of endogenous risk factors falls on the age groups of $30-39$ and $40-49$ years.

3. The proposed project of an epidemiological study of polypathy in populations of LFV and their risk factors contributes to the development of optimal approaches to the prevention of multiple diseases at the individual and community levels.

\section{REFERENCES}

1. Abdullaev R.B. Features of the clinical course, prevalence and new approaches to the treatment of gastric ulcer and duodenal ulcer in the South Aral region // Abstract of the thesis.... Doctor of Medicine - Tashkent. - 2002 .-- S. 10-15.

2. Abdusamatov U. A. Pregnancy and kidney pathology (clinical and echographic study) // Diss ... cand. medical sciences. - Tashkent. - 1998 .-- S. 152-155.

3. Akanov A.A. Epidemiology and prevention of the main chronic non-infectious diseases among the rural population of the Republic 
of Kazakhstan // Abstract of the thesis ...

d.m.s. - Bishkek. - 1991 .-- S. 23-26.

4. Vlasov V.V. An introduction to evidencebased medicine. - M.-Mediasphere. - 2001 .- S. 158-174.

5. Kayumov U.K. et al. Cardiovascular diseases in the structure of mortality of the female population 20-59 years old in the city of Tashkent // In the book, actual problems of extragenital diseases. Bukhara. - 1999.- P.175-177

6. Dzhuraeva M.A. Population studies of the main chronic non-infectious diseases among the urban and rural population of the Fergana Valley, risk factors and methodological aspects of prevention // Abstract of thesis.... Ph.D. - Tashkent. 1999. - P.2-12.

7. Oganov R.G., Maslennikova G.Ya. Cardiovascular diseases in the Russian Federation in the second half of the twentieth century: trends, possible causes, prospects // Cardiology. - 2000. - No. 6. - P.6-

7.

8. Raimjonov A. Dizionia and its relationship with the prevalence of major extragenital diseases among women of fertile age // Diss ... Ph.D. - Andijan. - 2002. - P.12-28.

9. Shamurova Yu.Yu. et al. Epidemiology and prevention of multiple chronic diseases (polypathies) in the rural population // Materials of the conf. "Ohr and fortified. public health ". - Moscow. - 2001 .-- P.102.

10. Sheikhman M.M. Extragenital pathology and pregnancy // Leningrad. - 1987. - P.6478. 